\title{
AC 2008-898: CONTINUOUS IMPROVEMENT OF ENVIRONMENTAL ENGINEERING CURRICULUM IN A CE ACCREDITED PROGRAM
}

\section{Kevin Bower, The Citadel}

Dr. Bower is an Assistant Professor in the Department of Civil and Environmental Engineering at The Citadel in Charleston, SC. Prior to his employment at The Citadel, he worked as an environmental engineer in Akron, Ohio. He received a Ph.D. in Environmental Engineering from The University of Akron and specialized in modeling carcinogenic chemical production in the drinking water distribution system. Dr. Bower was the 2005 Most Outstanding New Faculty at the ASEE-SE Conference and a New Faculty Fellow at the 2004 Frontiers in Education Conference. Dr. Bower is currently pursuing research in ethical and moral development in the engineering profession and how that relates to student learning.

\section{William Davis, The Citadel}

William Davis is an Associate Professor in the Department of Civil \& Environmental Engineering at The Citadel in Charleston, SC. He obtained a B.S. in Civil Engineering from the University of Alabama, M.S. from Auburn University and earned a Ph.D. in Transportation Engineering from the Georgia Institute of Technology. Dr. Davis is a member of ASEE, American Society of Civil Engineers, Institute of Transportation Engineers and Transportation Research Board. He serves as Chair of the Education and Student Chapter Committee for the Institute of Transportation Engineers - District 5. 


\title{
Continuous Improvement of Environmental Engineering Curriculum in a CE Accredited Program
}

\begin{abstract}
The development of the American Society of Civil Engineers (ASCE) Body of Knowledge (BOK) guidelines for assessment of program outcomes provides an excellent backdrop for monitoring and improving environmental engineering curriculum in a $\mathrm{CE}$ accredited program. A department wide process has been developed which allows faculty to monitor individual student learning as well as tracking changes made to course and curriculum level improvements. On an individual student basis, embedded indicators have been designed based on Bloom's taxonomy and are used to collectively measure student's cognitive performance as it relates to specific course goals. This process has been developed over the past several years and is currently in the first phase of adjustment and refinement. A systematic means of mapping previously adopted individual learning objectives to specific course goals for the four environmental engineering courses contained in the program is discussed in this paper. On the course and curriculum level improvements, a process has been developed to readily categorize types of changes being instituted and then tracking them from year to year. This process has served to facilitate a productive environment for data driven decision-making by the department and its faculty in lieu of anecdotally based approaches. The objective of this paper is to provide a useful summary as to how instructional material and course goals for environmental engineering courses contained within an undergraduate civil engineering curriculum are efficiently mapped, measured, evaluated and improved in support of quantifiable program outcome assessment. This paper identifies and delineates adopted departmental procedures used to facilitate systematic curriculum decision making, produce readily usable assessment documentation and sustain evidencebased collective faculty efforts occurring along a productive continuous improvement continuum.
\end{abstract}

\section{Introduction/Background}

In today's prevailing assessment-driven atmosphere of engineering education, faculty are being placed under increased demands to measurably link course instruction and student learning to curriculum-wide program outcomes. In addition, course modifications and curriculum improvements need to be implemented systematically within a transparent and documented manner that embodies the ideas of continuous improvement. Furthermore, it is not enough to merely measure outcomes and manage on-going modifications, effective civil engineering programs need to be able to plot a course of action on a broader horizon guiding change to achieve a vision of what the program should become over a 5 or 10 year period. The process has been created and implemented by faculty within the department to address important aspects of assessment within an efficient framework of documentation and decision making. This paper contains a discussion of these assessment components within the context of the four environmental engineering classes contained within the department's undergraduate 
curriculum. Specific aspects of the process and corresponding assessment oriented results are summarized along with supporting data and explanatory tabulations.

A critically important framework for assessment of civil engineering programs was established by the American Society of Civil Engineers (ASCE) that further expanded on ABET criteria to institute a Body of Knowledge (BOK) for civil engineering graduates. The ASCE-BOK [1] promulgates a wide variety of academic ideas and philosophies, including use of 15 program outcomes comprised of the eleven contained in ABET Criteria $3 \mathrm{a}-\mathrm{k}$, and four additional outcomes on specialized areas of civil engineering; project management, construction, and asset management; business and public policy; and leadership. Table 1 includes a list of all 15 program outcome criteria identifying both ABET and corresponding ASCE-BOK designations. For the purposes of this paper, program outcome criteria will be referenced based on ASCE-BOK designations (1-15). In addition to program outcomes, ASCE-BOK promotes adoption of six levels of Bloom's cognitive taxonomy to establish levels of competency students should attain across specified program outcomes. The six levels of Bloom's taxonomy are summarized as follows [2]:

- Knowledge consists of facts, conventions, definitions, jargon, technical terms, classification, categories, and criteria.

- Comprehension the ability to understand and grasp the meaning of material, but not necessarily to solve problems or relate it to other material.

- Application the use of abstract ideas in particular concrete situations.

- Analysis consists of breaking down complex problems into parts.

- Synthesis involves taking pieces and putting them together to make a new whole.

- Evaluation a judgment about a solution, process, design, report, material and so forth using expertise/experience in the area.

Table $1 \quad$ ABET/ASCE-BOK Comparison [1]

\begin{tabular}{cl}
$\begin{array}{c}\text { ABET } \\
\text { Criterion 3, a }-\mathrm{k}\end{array}$ & \multicolumn{1}{c}{$\begin{array}{c}\text { ASCE-BOK } \\
\text { Outcomes, } 1-15\end{array}$} \\
\hline $\mathrm{a}$ & 1. Technical core \\
$\mathrm{b}$ & 2. Experiments/analyze and interpret \\
$\mathrm{c}$ & 3. Design \\
$\mathrm{d}$ & 4. Multi-disciplinary teams \\
$\mathrm{e}$ & 5. Engineering problems \\
$\mathrm{f}$ & 6. Professional and ethical standards \\
$\mathrm{g}$ & 7. Communication \\
$\mathrm{h}$ & 8. Impact of engineering \\
$\mathrm{i}$ & 9. Life-long learning \\
$\mathrm{j}$ & 10. Contemporary issues \\
$\mathrm{k}$ & 11. Engineering tools \\
& 12. Specialized area of civil engineering \\
& 13. Project management, construction, and asset management \\
& 14. Business and public policy \\
\end{tabular}


Many academic institutions have started the process of addressing how ASCE-BOK outcomes and assessment criteria can be integrated into the civil engineering curriculum by conducting internal investigations, creating detailed assessment plans and maps, and developing on-line assessment tools. The authors have previously presented a detailed literature review in Bower et al.[3]. References have been included for the reader's convenience [4-10].

The objective of this paper is to provide a useful summary as to how instructional material and course goals for environmental engineering courses contained within an undergraduate civil engineering curriculum are efficiently mapped, measured, evaluated and improved in support of quantifiable program outcome assessment. This paper identifies and delineates adopted departmental procedures used to facilitate systematic curriculum decision making, produce readily usable assessment documentation and sustain evidence-based collective faculty efforts occurring along a productive continuous improvement continuum.

\section{Overview of Program Assessment Process}

Department of Civil and Environmental Engineering faculty have adopted an overall assessment process that is focused on comprehensively linking all activities of the department to 1-3 educational program objectives and 1-15 program outcomes.

Continuous improvement across the department is based on faculty members completing an end-of-semester course assessment report for each course taught during the term. Standardized formatting allows information to be readily compiled and analyzed from a variety of academic and administrative perspectives. With the underlying need to aggregate course data on a course tract, technical discipline and curriculum-wide basis, it was concluded that for this process to be effective consistent course goals were a necessity so that every time a course was offered, regardless of individual instructor or particular semester the course goals would be identical. Sub-groups of CEE faculty, referred to as course content subcommittees, worked on a course-by-course basis to adopt common course goals, link outcomes, and agree on competency (Bloom's) levels that students should attain upon completion. Sub-groups were formed based on classes previously taught and areas of expertise. This process is graphically depicted in Figure 1, along with subsequent tasks described herein, and includes feedback loops for continuous improvement.

Once common course goals were adopted, uniform BOK program outcomes were aligned with each course goal. Consistent levels of expected student competence were then established, after which two types of useful data aggregations were possible. The highest order of data aggregation was created at the department-wide curriculum level where all courses and course goals were reflected across 1-15 ASCE-BOK outcomes and at assigned 1-6 Bloom's competency levels. Furthermore, sub-aggregations were produced for discipline specific courses within the major curriculum concentrations including environmental, structural, transportation and geotechinical. This allowed a more detailed analysis of student learning and instructional continuity across interconnected courses within a meaningful context of related course content. 


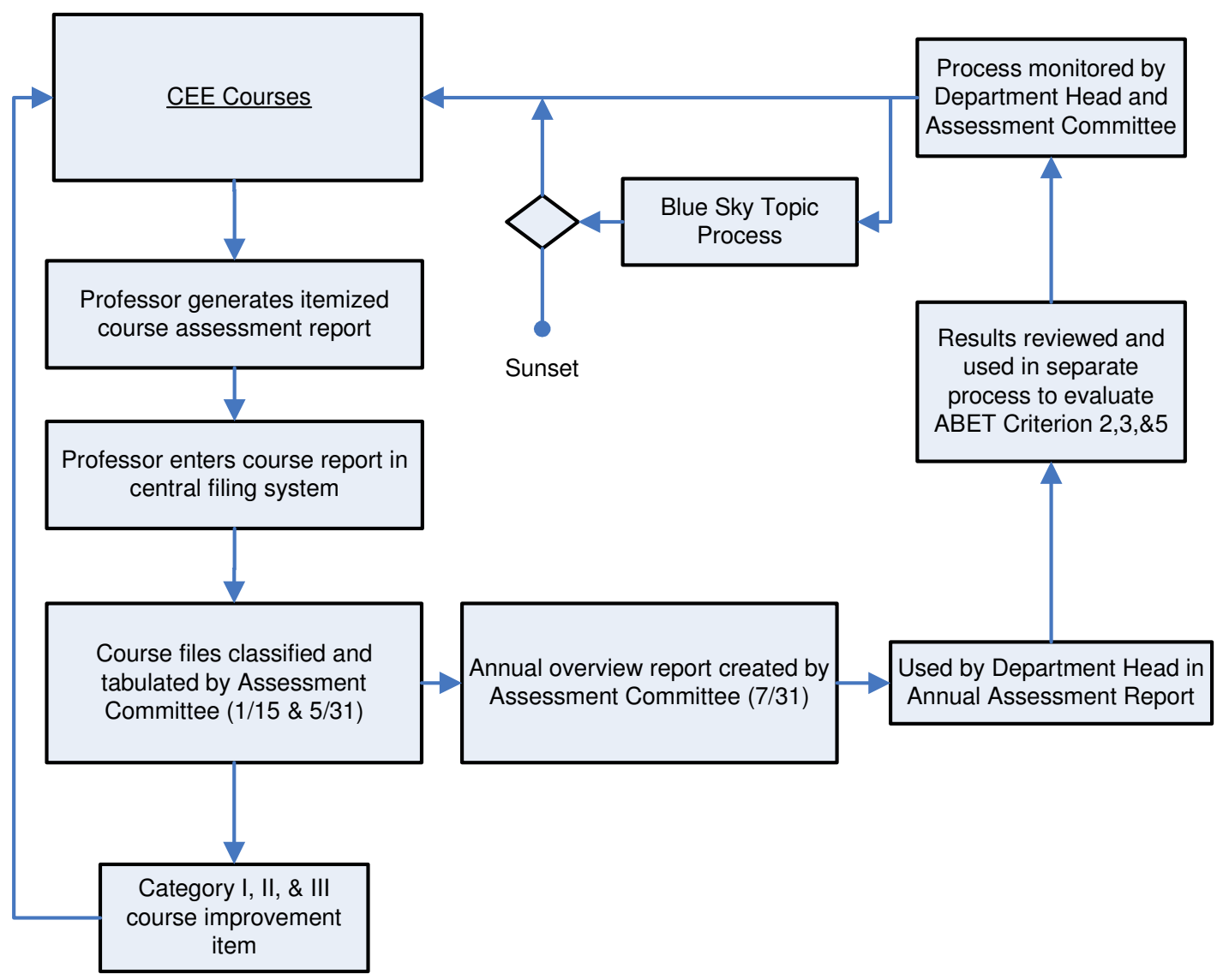

Figure $1 \quad$ Course Evaluation Process

Course curriculum outcomes are combined with other student development activities such as ASCE Student Chapter activities, leadership development, and student employment/internships to create a comprehensive view of the overall student experience. As this approach combines a large amount of information in a single tabulation, extracting meaningful information for specific improvement purposes can prove difficult. Even though a comprehensive view is useful, an additional step was created in which course goal data, learning objectives, embedded indicators, course improvements and long-term curriculum changes are aggregated along specific civil engineering disciplines.

This paper focuses on environmental engineering data aggregation and assessment issues. This level of aggregation creates a workable economy of scale for identifying continuity between related courses and targeting improvements to enhance student learning. Environmental engineering courses within the curriculum are identified and assessment activities are described with respect to embedded indicators, learning objectives, ongoing course improvements and future blue sky long-term changes. As the majority of data collected in support of these particular assessment activities is assimilated through the department's end-of-term course closure reporting system, a description of this is also included in the paper. 


\section{Environmental Engineering Courses in Curriculum}

The department's educational philosophy is predicated on the idea of providing students with a broad based education including a firm foundation in design. In support of this goal the departmental curriculum contains four courses in environmental engineering that sequentially direct undergraduate student development through exposure to a variety of environmental engineering topics with a specific emphasis on the production of design. The following are descriptions of the four environmental engineering courses currently offered within the civil engineering curriculum:

\section{Civl 312 - Introduction to Environmental Engineering}

Introduction to water, air, solid and hazardous waste (including radioactive material, and noise pollution and its control.) Included are social and ethical considerations, legal and regulatory principles, risk analysis, the effect of pollutants in the environment, and the engineering principles governing the generation and control of these pollutants.

Civl 408 - Water and Wastewater Treatment

Introduction to engineering design principles and practices including water use, quality standards for drinking water, water treatment systems, determining the quantity of wastewater, design of sanitary sewers, quality criteria for surface waters, and wastewater treatment systems.

Civl 419 - Environmental Engineering Laboratory

Accomplishment of chemical, physical, and microbiological determinations used in the experimentation of water and wastewater. Laboratory analysis to evaluate water quality will be performed, such as biochemical oxygen demand, suspended solids, $\mathrm{pH}$, alkalinity, and others. A minimum of one laboratory exercise will involve the use of the computer to evaluate laboratory data.

\section{Civl 422 - Comprehensive Design Project in Environmental Engineering}

Application to civil engineering principles, through group studies and lecture, to develop a solution for a comprehensive engineering problem devoted to water resources/ environmental engineering.

\section{Course Closure Reports and Assessment Item Tracking}

A major emphasis of the Departmental assessment process is specifically focused on systematic evaluation of all required Civil Engineering courses within the curriculum. A course review process was established in 2003 and subsequently modified through adopted revision by Department faculty for the past four and a half years. The process requires faculty to generate an end-of-term course assessment report and to submit the report into a central filing system. Course reports are then reviewed, processed, aggregated and classified by the Department's Assessment Committee and an overview report is published to create a comprehensive summary of what has occurred over the academic year with respect to course assessment. This report is assimilated into the Department Head's broader annual report and is formally reviewed by a variety of stakeholders' including Department Faculty, Dean of Engineering, and external Department Advisory Council. This process provides a means to review and monitor 
improvement to the course curriculum, document modification to the assessment process, and manage change along a sustainable continuous improvement continuum.

Review and tracking of course related issues are conducted through submission of endof-the term course closure reports that uniformly addresses the following administrative, instructional and educational course specific components:

- identification of ABET course information,

- mapping of course goals to program outcomes and Bloom's Taxonomy levels,

- evaluation of student attainment of course goals with respect to departmental standards,

- use and documentation of embedded indicators for evaluation of course goals,

- generation and resolution tracking of on-going course improvement action items.

As part of the established operating procedure of the Department all faculty are required to submit end-of-term course closure reports based on an adopted standardized reporting format and use of an established tracking process to follow-up on assessment related teaching and course content issues. For the required courses within the curriculum this amounts to approximately 31 courses and 80 course sections per year. Data from end-ofterm course closure reports is aggregated for evaluation in a variety of forms with the primary intention of establishing a framework for continuous improvement and supporting the departmental assessment process. Uses, basis and limitations of course closure report data aggregations with respect to topics presented in the paper are summarized follows:

Program Outcome Matrix - A department-wide matrix is created annually updated to provide a comprehensive distribution of all course goals for program outcomes $1-15$ and Bloom's Taxonomy $1-6$ levels. Specific instructional thresholds were taken from ASCE's BOK II and subsequent coordination, via course content subcommittees, occur to insure these criterion were consistently applied across course offerings and closely adhered to on a year-by-year basis.

Embedded Indicators - Student performance on attainment of established course goals is evaluated and documented through use of embedded indicators, typically involving either test questions, class assignments or multifaceted projects. A departmental standard assists faculty with selecting the proper assessment tool at appropriate level's of Blooms. The intent of this initiative to establish one embedded indicator for each course goal for all courses taught within the Department.

Learning Objectives - Not yet formally aggregated for the curriculum with regard to assessment use. Faculty have latitude to develop, track and change as they wish as long as adopted course goals and program outcomes are being supported through student learning and course instruction.

Course Improvements and Assessment Item Tracking - Faculty generated course improvement items are classified, tracked and implemented based on level of impact on the curriculum, faculty as issues that need to be addressed: I.) only by self, II.) by course content subcommittee, or III.) by department faculty as a whole. These items are tracked and aggregated at each level during the academic year to provide a detailed perspective of on-going efforts being implemented to improve the civil engineering curriculum. 


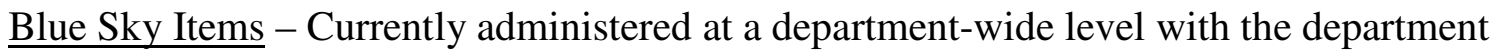
head and entire faculty involved in generating, evaluating, prioritizing, implementing and tracking each Blue Sky improvement item.

\section{Embedded Indicators}

Embedded indicators are used extensively for all required courses in the Department's curriculum as an assessment tool for collectively measuring student comprehension with respect to specific course goals at appropriately assigned Bloom's level of cognitive performance. These tools are externally established prior to the student activity, and structured in a manner to take advantage of test questions and projects already being throughout the term of the course.

Prior to teaching a course faculty identifies the tool that will be used to measure each of the course goals, which must be measured only once for each class. Table 2 outlines acceptable tools that faculty can use to demonstrate appropriate levels of cognitive performance. If a faculty believes they have an assessment tool that can be used at a different level of Bloom's than designated in Table 2, then the Course Content Subcommittee (predetermined group of at least three faculty whose area of expertise falls within the course subject matter) meets to evaluate and develop a consensus. Throughout the semester students are assessed using the designated tool. If the average grade on the tool is $70 \%$ or higher, it is determined students have met the requirement of the corresponding course goal and achieved the departmental standard. Example work from three students for each tool is included with a summary embedded indicator coversheet, which summarizes assessment of student performance.

Tables 3 and 4 present how the four environmental engineering courses in the curriculum map against the department Program Outcomes at levels of Bloom's Taxonomy. For Table 3 the course number has been coded into the matrix when at least one course goal expects students to achieve a program outcome at a designated level of Bloom's Taxonomy. Table 4 expands on that tabulation by providing the number of course goals within the environmental engineering curriculum where students are expected to achieve a program outcome at a designated level of Bloom's Taxonomy. These tabulations are structured to allow evaluation of meaningful relationships between educational subject matter, program outcomes, and competency levels. From a review of these tabulations, a number of interesting and useful quantifiable observations regarding the environmental engineering curriculum were noted:

- 29 assessment measurements are made through the four environmental engineering classes within the curriculum.

- 19 different Blooms' Levels are measured for 11 of the 14 department program outcomes. For environmental engineering to be a legitimate focus area within the civil engineering curriculum, the associated curriculum should contribute to a broad number of Program Outcomes at various levels of cognitive performance.

- As expected, lower level courses have goals that map to lower levels of cognitive performance. From the perspective of a student learning environmental engineering material, it is critical that knowledge and skill sets are constructed and that subsequent expectation levels increase with course level. 
Table 2 Embedded indicator tool at appropriate levels' of Blooms Taxonomy

\begin{tabular}{|c|c|c|c|c|c|c|c|}
\hline Embedded Indicators & • & 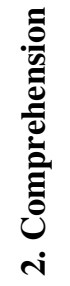 & 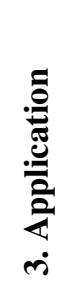 & $\begin{array}{l}\frac{n}{\pi} \\
\frac{\pi}{\pi} \\
\frac{\pi}{\tilde{T}} \\
\dot{r}\end{array}$ & 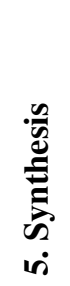 & 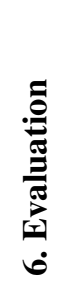 & Documentation \\
\hline True/ False Questions & $\mathbf{X}$ & $\mathbf{X}$ & & & & & Test or Quiz Question \\
\hline Matching Questions & $\mathbf{X}$ & $\mathbf{X}$ & & & & & Test or Quiz Question \\
\hline Fill In Questions & $\mathbf{X}$ & $\mathbf{X}$ & & & & & Test or Quiz Question \\
\hline Multiple Choice Questions & $\mathbf{X}$ & $\mathbf{X}$ & $\mathbf{X}$ & & & & Test or Quiz Question \\
\hline Short Answer Questions & $\mathbf{X}$ & $\mathbf{X}$ & $\mathbf{X}$ & $\mathbf{X}$ & & & Test or Quiz Question \\
\hline Calculation Based Problems & $\mathbf{X}$ & $\mathbf{X}$ & $\mathbf{X}$ & $\mathbf{X}$ & & & Test or Quiz Question \\
\hline Essay Questions & $\mathbf{X}$ & $\mathbf{X}$ & $\mathbf{X}$ & $\mathbf{X}$ & & & Test or Quiz Question \\
\hline Research Papers & $\mathbf{X}$ & $\mathbf{X}$ & $\mathbf{X}$ & $\mathbf{X}$ & $\mathbf{X}$ & $\mathbf{X}$ & Entire Paper \\
\hline Lab Reports & $\mathbf{X}$ & $\mathbf{X}$ & $\mathbf{X}$ & $\mathbf{X}$ & $\mathbf{X}$ & $\mathbf{X}$ & Lab Report \\
\hline Design Problems & $\mathbf{X}$ & $\mathbf{X}$ & $\mathbf{X}$ & $\mathbf{X}$ & $\mathbf{X}$ & $\mathbf{X}$ & Project \\
\hline Capstone Projects & $\mathbf{X}$ & $\mathbf{X}$ & $\mathbf{X}$ & $\mathbf{X}$ & $\mathbf{X}$ & $\mathbf{X}$ & Project \\
\hline
\end{tabular}

- Consistent with the pervious observation, a lower level class provides the necessary foundation for higher levels of cognitive performance within a Program Outcome. In cases where no course appears at lower levels, the student is obtaining necessary knowledge foundation from somewhere else within the curriculum. This creates a learning environment in which student understanding of the multidisciplinary nature of engineering and is consistent with the department's philosophy on the need for a broad based education.

- Table 3 illustrates that Environmental Engineering Capstone provides the most diverse coding with course goals appearing at the highest cognitive level in the area of design. This is consistent with the requirement that this class should draw from a wide array of academic elements and technical knowledge gained from within the curriculum to meet the challenges of a realistic design problem. 
Table 3 Program Outcomes Matrix with Environmental Engineering Classes Coded by their Course Number.

\section{Evaluation}

5. Synthesis

4. Analysis

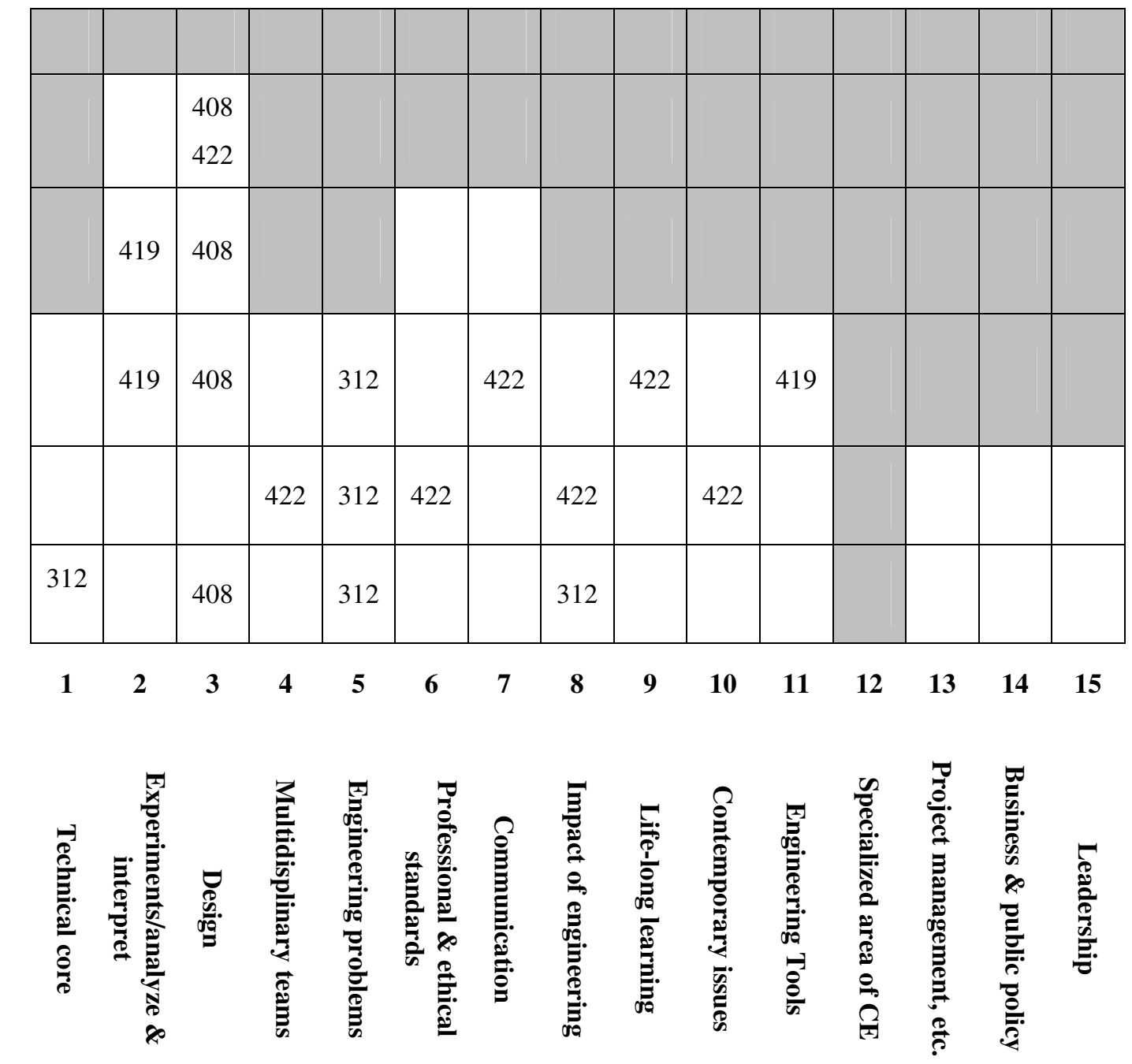

3. Application

2. Comprehension

1. Knowledge

- Table 4 illustrates that most course goals from the environmental engineering curriculum are coded at the application level or above. This is expected since the first class in environmental engineering does not occur until the first semester of the junior year. At that point in the curriculum, students have been exposed to fundamental elements for most program outcomes and are ready to conduct more critical work in these areas.

- Most environmental engineering course goals are coded to program outcomes dealing with experimentation, design, and engineering problems. Since there are only four courses within the curriculum dealing with environmental engineering, there is not enough time to bring in other diversified elements and still cover the necessary technical material. The sole opportunity to synthesize other elements is during the capstone class. 
Table 4 Program Outcomes Matrix with Environmental Engineering Classes Goals Coded (Number of Course Goals at Each Level.)

6. Evaluation

5. Synthesis

4. Analysis

3. Application

2. Comprehension

1. Knowledge

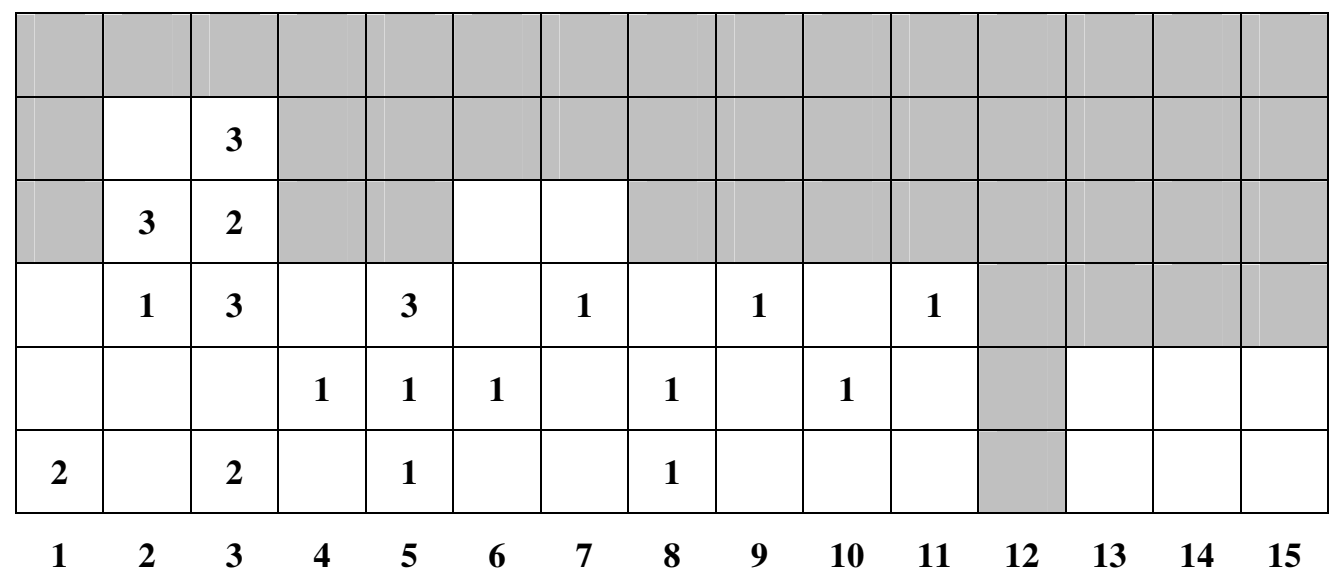

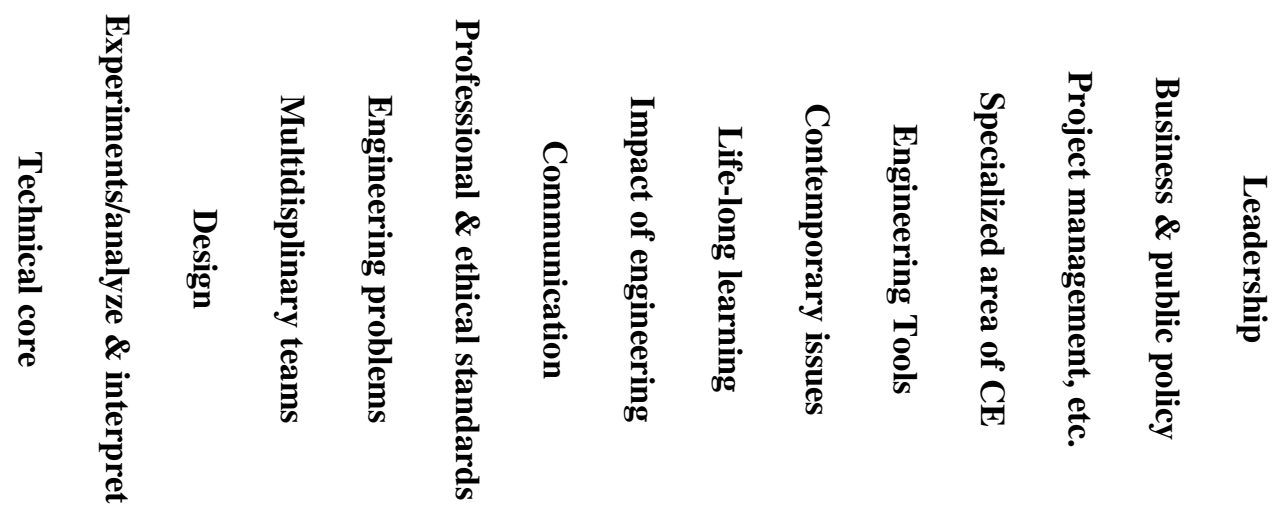

\section{Learning Objectives}

Specific learning objective are developed by the professor for three of the four classes within the environmental engineering curriculum. They are not provided in Civl 422 Environmental engineering capstone due to the fact that students are expected to generate their own learning objectives in an effort to develop their life - long learning skills. Learning objectives are given to students at the same time the reading assignment for the upcoming materials. They are intended to let the student know what the learning expectation are and how they will be held accountable for their own learning. They are written in $\mathrm{s}$ fashion that relates the objective is a specific and measurable fashion. This section of the paper investigates how the learning objectives relate to the published course goals.

Tables 5, 6, and 7 are matrix tabulations of the learning objectives provided mapped to the corresponding course objective at the appropriate level of Bloom's Taxonomy. The shaded and highlighted cell represents the level measured for assessment. If a " $\mathrm{D}$ " 
appears by the course goal it has been designated as a discretionary goal and is not required to be covered by the professor teaching the course. "WR" (writing assignment)and "DP" (design project) indicate requirements of the course which are not yet specified in the goals These tabulations are structured to allow evaluation of meaningful relationships between educational subject matter, program outcomes, and student competency levels. From a review of these tabulations, a number of interesting and useful quantifiable observations regarding the environmental engineering curriculum were noted:

Table 5 Learning Objectives for Civl 312 Introduction to Environmental Engineering Coded against expected levels of Blooms' Taxonomy.

6. Evaluation

5. Synthesis

4. Analysis

3. Application

2. Comprehension

1. Knowledge

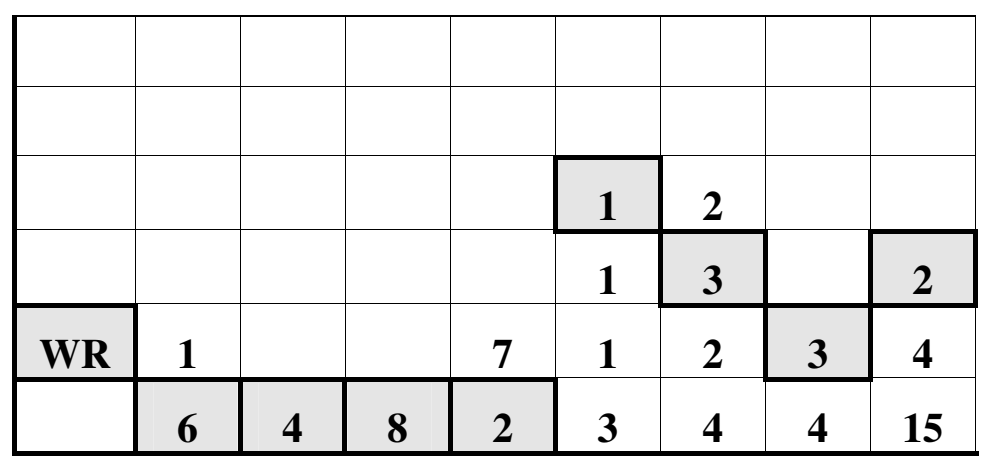

$\begin{array}{lllllllll}\text { 1. } & \text { 2. } & \text { 3. } & \text { 4. } & \text { 5. } & \text { 6. } & \text { 7. } & 8 . & 9 .\end{array}$ Course Goals

Table 6 Learning Objectives for Civl 408 Water and Wastewater Treatment Coded against expected levels of Blooms' Taxonomy.

6. Evaluation

5. Synthesis

4. Analysis

3. Application

2. Comprehension

1. Knowledge

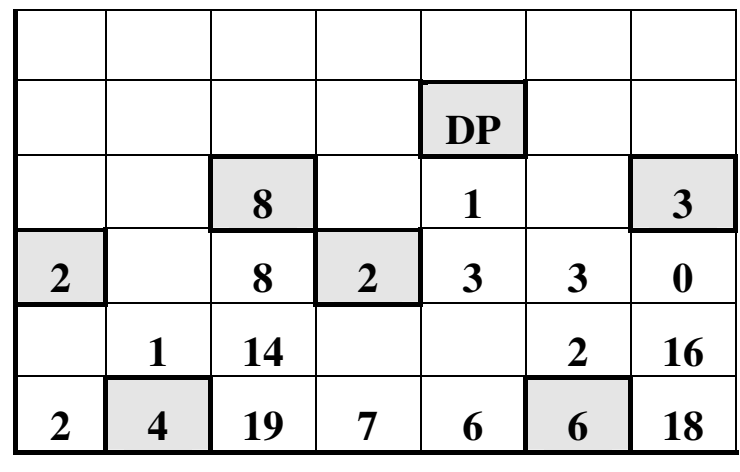

1. 2. 3. 4. $\quad$ 5. 6.6 . 7 .

Course Goals 
Table $7 \quad$ Learning Objectives for Civl 419 Environmental Engineering Laboratory Coded against expected levels of Blooms' Taxonomy.

\section{Evaluation}

5. Synthesis

4. Analysis

3. Application

2. Comprehension

1. Knowledge

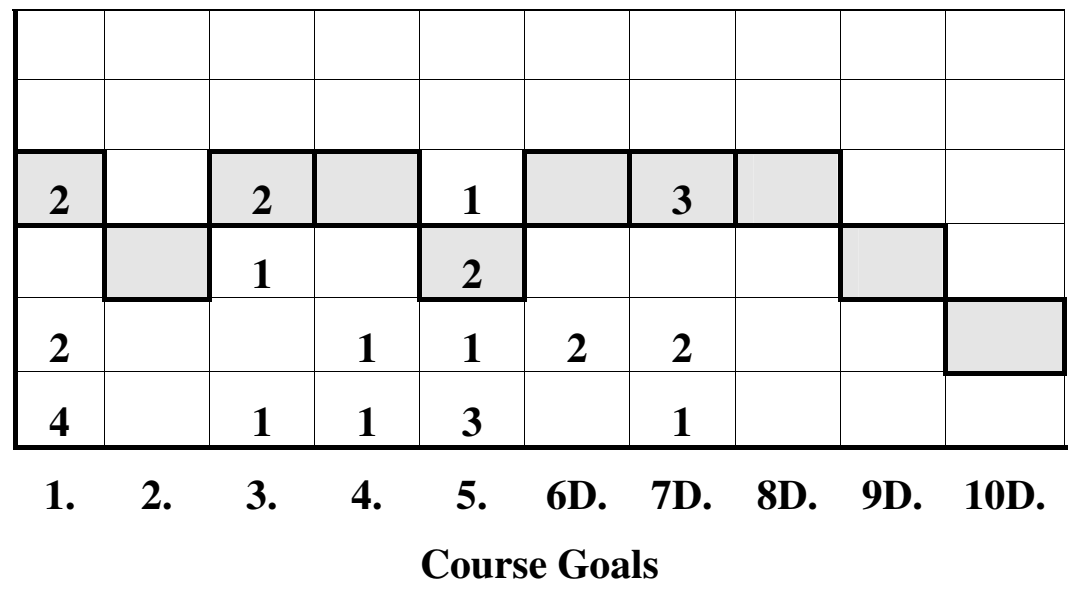

- There are 104 learning objectives for Civl 312 but only 73 directly map to course goals. This is the first class in the curriculum dealing specifically with environmental engineering issues and there are a few areas where basic material must be covered or reviewed in order to allow more insightful work to be conducted by students later in the course. Examples of this include groundwater terminology and chemistry review.

- There are 125 learning objectives for Civl 408. In this class all learning objectives map directly to a course goal. There are 29 learning objectives for Civl 419.

- For the two "lecture classes" (Civl 312 \& 408), there is a natural progression of learning objectives with more aligned at lower cognitive levels building up to a fewer at the level were assessment occurs.

- In all cases except two, there are multiple learning objectives at the Bloom's level measured for course assessment. Civl 408 (Table 6) has a substantial design project which is used for assessment purposes. Civl 312 (Table 5) uses several current events memos based on the Public Radio International broadcast entitled "Living on Earth." Having multiple learning objectives at the level of assessment allows the professor a wide variety of potential embedded indicators to choose from when setting up the assessment plan at the beginning of each semester.

\section{Course Improvement Items - On-going Change}

Course improvements items are generated by faculty and formally identified through the end-of-term course closure reporting process. Over the course of the past four-and-ahalf-years a large number of improvement items have been generated for required courses within the civil engineering curriculum. Improvements items are classified for follow-up action and tracking based on the following criteria:

Level I - Minor items that can be addressed directly by professor to improve course content or student learning environment for subsequent course offerings. This type item typically involves professor notes and reminders to himself/herself. No actions are 
required for review and approval. Tabulation of the quantity of these items is maintained through the Annual Course Assessment process.

Level II - Intermediate items require coordination with other professors teaching the same course or other interrelated courses. A classic example of this type issue would be changing the course textbook. Other issues such as agreeing upon common course goals and assessment criteria also fall into this category. A draft resolution proposal is developed by professor/discipline team and is subsequently reviewed by the Assessment Committee as outlined in the CEE Course Assessment Process.

Level III - Major items require coordination with the Department's Curriculum Committee and CEE faculty. Recent examples include increasing the number of credit hours for a course, significantly changing the course syllabus and course modifications that could affect other courses. A draft resolution proposal is developed by professors, reviewed by the Department's Curriculum Committee and approved by CEE Department Faculty as outlined in the CEE Course Assessment Process. Major changes will also require involvement and approval from The Citadel's college-wide Curriculum Committee.

Table 8 provides an overview of improvement items generated and tracked for the four environmental engineering courses in the curriculum. In total 37-Level I and 23-Level II improvements were identified for action for the four environmental engineering courses. A more detailed breakdown of improvement items for Civl 312 is provided in Table 9. This shows the progression of how issues are identified and resolved over the period of four-and-a-half years. Most ideas are evaluated and resolved resulting in various course improvements in student instruction, course content, or assimilation of new technology or teaching methods. Some ideas are considered and then dismissed through an evaluation and assessment process conducted at the appropriate level of coordination with other faculty in the department, while others are resolved over a number of semesters. Each of the four environmental courses has a similar sequential listing of improvement items and subsequent resolution action. This type organizational approach is useful for generating, evaluating and documenting course improvements within an overall departmental assessment context. Not only is it helpful in sustaining a commitment to the ideal of continuous improvement, it constitutes an efficient means of decision making within various size faculty work groups and provides a considerable amount of transparency with respect to decisions affecting curriculum.

Table 8 Overview of Improvement Items Generated and Tracked for the Four Environmental Engineering Courses in the Curriculum.

\begin{tabular}{lcccccccccc}
\hline & \multicolumn{2}{c}{2003} & \multicolumn{2}{c}{2004} & \multicolumn{2}{c}{2005} & \multicolumn{2}{c}{2006} & \multicolumn{2}{c}{2007} \\
Course & I & II & I $^{2}$ & II & I & II & I & II & I & II \\
\hline 312 & 2 & 3 & 1 & 2 & 3 & & 2 & & 3 & \\
408 & 4 & 1 & 1 & 1 & 3 & 1 & 2 & 2 & 3 & \\
419 & -- & -- & 3 & & 2 & 1 & 1 & 1 & 1 & 2 \\
422 & -- & -- & 3 & 2 & 1 & 3 & 1 & 1 & 1 & 1 \\
\hline Total & $\mathbf{6}$ & $\mathbf{4}$ & $\mathbf{8}$ & $\mathbf{7}$ & $\mathbf{9}$ & $\mathbf{5}$ & $\mathbf{6}$ & $\mathbf{4}$ & $\mathbf{8}$ & $\mathbf{3}$ \\
\hline
\end{tabular}


Table 9 Specific Improvement Items Generated and Tracked for Civl 312 Introduction to Environmental Engineering.

\begin{tabular}{|c|c|c|c|c|c|}
\hline $\begin{array}{c}\text { Course } \\
\text { No. }\end{array}$ & $\begin{array}{c}\text { Year } \\
\text { generated }\end{array}$ & Level & Item description & $\begin{array}{c}\text { Year } \\
\text { addressed }\end{array}$ & Action taken/status \\
\hline \multirow[t]{5}{*}{312} & 2003 & I & Course work documentation for ABET & 2004 & Resolved - complete \\
\hline & & I & Incorporate active learning instruction & & In progress \\
\hline & & II & Incorporate GIS material & & In progress \\
\hline & & II & Change textbook & & Resolved - complete \\
\hline & & II & Reduce number of course outcomes & & Resolved - complete \\
\hline \multirow[t]{3}{*}{312} & 2004 & I & Incorporate active learning instruction & 2005 & In progress \\
\hline & & II & Incorporate GIS material & & Resolved - omitted \\
\hline & & II & Modify course goals & & Resolved - complete \\
\hline \multirow[t]{3}{*}{312} & 2005 & I & Incorporate active learning instruction & & Partially complete \\
\hline & & I & Develop mini labs for use in course & & Partially complete \\
\hline & & I & Develop Chemistry review & & Resolved - complete \\
\hline \multirow[t]{2}{*}{312} & 2006 & I & Incorporate active learning instruction & 2007 & Partially complete \\
\hline & & II & Develop mini labs for use in course & & Partially complete \\
\hline \multirow[t]{3}{*}{312} & 2007 & I & Incorporate active learning instruction & & \\
\hline & & I & Develop mini labs for use in course & & \\
\hline & & I & Incorporate POD casts for use in course & & \\
\hline
\end{tabular}

\section{Blue Sky Changes - Long-term Improvement}

Large scale improvements to the environmental engineering courses and curriculum can be made through the Blue Sky path. Blue Sky topics are intended to provide a means to motivate faculty to develop ideas that play to their individual strengths and are important for the future and vision of the department. The term Blue Sky has been selected to represent the nature of the initial idea discussion that is intended to be a "What if... the sky were always blue" discussion where there are no limitations of time, money, or politics when dealing with a particular curricular developmental issue." The Blue Sky is intended to be a topic, which is broad in nature and requires collaboration between 
multiple faculty, multiple course content subcommittees, and/or multiple department wide committees. Topics follow a minimum three-year cycle of idea development, implementation, and assessment. The following steps outline the process in more detail:

Develop Idea and Action Plan - A Year of Dialogue (Year 1)

A topic is selected by the department head and is presented to the faculty typically during the fall retreat. An open discussion with the department as a whole lasting no more than 45 minutes follows. The department head maintains an environment which is completely open and where ideas are present with no regard to financial, political, or personal limitations. The only direction provided by the department head is to keep the topic consistent with the original intent. After the fall retreat, faculty members are encouraged to begin a year of dialogue on the topic. The intent is to continue raw idea development, begin to identify factors critical to the success of the idea, and identify response variables with potential assessment tools.

Implementation and Data Gathering (Year 2)

Based on ideas presented during the year of dialogue, the department head presents a specific course of action to the faculty, typically during fall retreat. The course of action identifies a refined issue to be assessed and establishes an ad hoc committee to deal with specific implementation issues, specific tools to be used to measure the response variable, and establishes a threshold for improvement that will constitute a successful change. Data will be gathered throughout the year.

\section{Assessment and Reevaluation of Action Plan (End of Year 2 and annually thereafter)}

The results from the previous year will be compiled by the ad hoc committee and presented to the faculty during the fall retreat. After which one of the following assessments and course of action will be taken:

- $\quad$ Change is successful and is permanently incorporated into the curriculum and department assessment process

- $\quad$ Change is not successful. Sunset the idea.

- A clear assessment cannot be made and the action plan is reevaluated or additional data is gathered. The ideas are returned to the Implementation and Data Gathering Phase and evaluated annually.

\section{Current Blue Sky Topics which relate to Environmental Engineering}

The following is an example of a potential Department wide Blue Sky topic that could impact the environmental engineering curriculum within the Department:

Topic:

Enhance Faculty Collaboration on Improving Student Learning

Initial Discussion Topic:

Challenge the faculty to develop innovative improvements to classroom instruction. How can the faculty work outside of our main area of expertise to improve student learning? What technology is available to improve student learning that we the faculty currently utilizing? 


\section{Current Status:}

Year 1 - Year of the dialogue: several ideas such as podcasting and formative assessment are currently being pursued.

\section{Conclusions}

Use of departmental assessment methods to specifically evaluate the four environmental engineering courses contained within the department's curriculum provides an appropriately focused level of evaluation and analysis that is useful in conducting meaningful assessment and instituting effective change. Benefits of these methods include:

- Consistent instruction of all four environmental engineering courses using the same course goals linking to equivalent program outcomes at corresponding levels of Bloom's.

- A system that provides an established linkage of learning objectives, course goals, and program outcomes for use in optimizing student instruction and supporting program assessment.

- Use of an embedded indicator for each course goal within an overall department plan that aligns course instruction with appropriate program outcomes and provides a quantifiable means of measuring student attainment of outcomes.

- Use of a systematic approach for collective decision making with respect to curriculum modification and environmental engineering course improvement for on-going and long-term changes.

- Use of a departmental process entitled "Blue Sky" to identify and prioritize longterm improvement topics through a rigorous analytically driven decision process

- Use of a reporting, evaluation, tracking and results oriented course assessment process that efficiently produces documentation and assimilates data within the context of departmental assessment.

Application of department assessment methods in specified areas of concentration for environmental engineering in the civil and environmental engineering curriculum, and subsequent analysis of course goals using ASCE-BOK outcomes and Bloom's levels of competency constitute an effective framework and foundation for establishing a process of continuous improvement and curriculum assessment. Through these efforts a functional data structure describing the instructional progression of students within a defined discipline tract such as environmental engineering is founded upon the creation of meaningful linkages between educational subject matter, program outcomes, and competency levels. As faculty periodically review, regulate, and refine the course curriculum within this organizational framework of analysis, process documentation, appropriately reflective of continuous improvement, is readily produced in a succinct and efficient manner.

Use of this framework allows the extensive work invested by the department in assessment efforts to be more disciplined and systematically focused upon specific 
improvement needs, predicated on better organization of course goals and outcomes, with the tracking of results for this method demonstrating a better manner of department-wide aggregation of data reflective of a comprehensive approach to program and curriculum assessment. In the absence of a solid organizational structure, improvements have had the appearance of being identified and addressed randomly verses systematically. The underlying objective of these evaluation procedures and future expansion to address comprehensive curriculum assessment is to maintain a comprehensive, well-integrated, and up-to-date curriculum that prepares students for professional practice and/or graduate work. Furthermore, development and execution of these organizational approaches for curriculum analysis and course improvement are intended to create an engaging means for faculty to address program assessment requirements and to seamlessly create recorded evidence needed to support ABET documentation for self study report preparation and accreditation reviews.

Future Steps:

- Finish developing learning objective for Civl 419 Environmental Engineering Laboratory.

- Require students in Civl 422 Environmental Engineering Capstone to provide documentation to the professor of learning objective prior to the required teach meetings. This will allow for better tracking and documentation of life-long learning skill development.

- Apply this structure to other course content areas within the Department

- Expand course tracking to include specific learning objectives in all areas within the curriculum.

\section{References}

[1] Civil Engineering Body of Knowledge for the 21st Century, Preparing the Civil Engineer for the Future, Committee on Academic Prerequisites for Professional Practice American Society of Civil Engineers, Reston, VA, Jan. 2004

[2] Rogers, G. M. (2004). "Assessing Planning Flow Chart." Rose-Hulman Institute of Technology, Terre Haute, IN.

[3] Bower, K.C., Davis, W. J., and Mays, T.M. (2005). "Meaningful Learning Environment by Design: Systematic Curriculum Assessment to Enhance Sequential Linkage of Course Goals and Objectives." 35th ASEE/IEEE Frontiers in Education Conference, Indianapolis, IN.

[4] Kevin C. Bower, Kenneth P. Brannan, and William J. Davis (2006). "Sequential Course Outcome Linkage: A New Look at Environmental Engineering Curriculum in a Civil Engineering Program.” ASEE National Conference - Environmental Engineering Division, Chicago, IL.

[5] Robinson, M., and Sutterer, K. "The ASCE-BOK A Case Study of the Evaluation and Design of a BOK Curriculum." 2004 ASEE Annual Conference and Exposition, Salt Lake City, Utah.

[6] Bailey, Margaret, R. Bruce Floersheim, Stephen J. Ressler, Course Assessment Plan: A tool for Integrated Curriculum Management, Journal of Engineering Education, Oct. 2002, 425-434.

[7] Karimi, Amir, Keith Clutter, Alberto Arroyo, An Example of Course and Program Assessment, Proceedings of the 2004 American Society of Engineering Education Annual Conference \& Exposition, American Society for Engineering Education, Salt Lake City, UT, June 2004. 
[8] Colwell, Joy L., Jana Whittington, James B. Higley, Tools for Using Course-Embedded Assessment to Validate Program Outcomes and Course Objectives, Proceedings of the 2004 American Society of Engineering Education Annual Conference \& Exposition, American Society for Engineering Education, Salt Lake City, UT, June 2004.

[9] Scachitti, Susan, Gregory Neff, James Higley, The Next level in TC2K: Continuous Quality Improvement, Proceedings of the 2004 American Society of Engineering Education Annual Conference \& Exposition, American Society for Engineering Education, Salt Lake City, UT, June 2004.

[10] Standardizing Outcomes Assessment Allows Faculty to Focus on Student Learning, Proceedings of the 2003 American Society of Engineering Education Annual Conference \& Exposition, American Society for Engineering Education, Nashville, TN, June 2003. 